\title{
THE FOUNDATION GPS WATER VAPOR INVERSION AND ITS APPLICATION RESEARCH
}

\author{
Rundong Liu ${ }^{1}$, Taoye Lee ${ }^{1, *}$, Huaquan Lv $^{1}$, Chengcheng Fan ${ }^{1}$, Qing Liu ${ }^{1}$ \\ ${ }^{1}$ Guangxi Zhuang Autonomous Region Institute of Remote Sensing Information Surveying and Mapping, 530023 Nanning, China - \\ 634604115@qq.com
}

Commission VI, (WG III/8)

KEY WORDS: Global Positioning System(GPS), Tropospheric delay, Wet delay, Inversion of water vapor, Precipitable water vapor

\begin{abstract}
:
Using GPS technology to retrieve atmospheric water vapor is a new water vapor detection method, which can effectively compensate for the shortcomings of conventional water vapor detection methods, to provide high-precision, large-capacity, near real-time water vapor information. In-depth study of ground-based GPS detection of atmospheric water vapor technology aims to further improve the accuracy and practicability of GPS inversion of water vapor and to explore its ability to detect atmospheric water vapor information to better serve the meteorological services. In this paper, the influence of the setting parameters of initial station coordinates, satellite ephemeris and solution observation on the total delay accuracy of the tropospheric zenith is discussed based on the observed data. In this paper, the observations obtained from the observation network consisting of 8 IGS stations in China in June 2013 are used to inverse the water vapor data of the 8 stations. The data of Wuhan station is further selected and compared with the data of Nanhu Sounding Station in Wuhan The error between the two data was between $-6 \mathrm{~mm}-6 \mathrm{~mm}$, and the trend of the two was almost the same, the correlation reached $95.8 \%$. The experimental results also verify the reliability of ground-based GPS inversion of water vapor technology.
\end{abstract}

\section{INTRODUCTION}

In July 2013, Yan'an, Shaanxi Province, sustained heavy rainfall caused serious natural disasters such as landslides, debris flows and floods. As of the 26th, in 158 villages, towns and neighborhoods and central communities in 13 counties and districts of Yan'an City, landslides and houses collapsed 2.69 Million, 936,000 people affected. In May 2014, Shenzhen suffered heavy rainstorm in the past five years and some 300 waterways accumulated in the city. Bao'an District, State Road 107, Longhua New District Fu Long Road, Shenzhen North Station Tunnel, Nanshan District, Taoyuan Road, Changxing Road and other water more than 1 meter, the city a total of about 2,500 vehicles flooded. The city about 50 area waterlogging. The torrential rain caused direct economic losses in Shenzhen about 80 million yuan. From June 18, 2016, 94 counties (cities and districts) in 17 cities (prefectures, cities directly under the central government, and forest areas) in Hubei Province all suffered natural disasters such as torrential rains and floods. Resulting in 19,620,300 person-times in the province were affected, 77 people were killed and 16 people were missing. 848,800 people were urgently relocated and need emergency rescue 581,700 people; 43,000 houses were damaged due to disasters, 92,000 were damaged in varying degrees; the affected area of crops was 1759.1 Thousands of hectares, of which 419.2 thousand hectares have been cut off; the direct economic loss of 45.47 billion yuan. This is only a small part of the world suffering from heavy rains and many more are happening constantly in the world. Of course, doing a good job in municipal administration is a very important part.
However, if we can forecast the accurate weather ahead of time and allow the government and people to make preparations for the prevention of heavy rain in advance, we can reduce a great deal of losses. Of course, there are also some means of detecting water vapor currently, but all have some limitations and are not enough to be applied to daily life. Therefore, there is a need to find a better way to detect atmospheric water vapor content in order to forecast the weather conditions and serve the needs of the community.

After the United States completed the development of the Global Position System in the 1990s, the system has been increasingly sought after in various fields due to its wide coverage, real-time continuity and all-weather work. In succession, all countries in the world have started the development of the GNSS system one after another. For example, Galileo of the EU, GLONASS of Russia, and BeiDou of our country are all the global positioning and navigation systems in the world. With so many advantages of GPS navigation and positioning systems over traditional detection methods, scholars around the world are wondering if the system can be used to detect atmospheric water vapor content. In the late 1980s, American scholars started the research in this area and conducted many experiments to prove the reliability of the method. Subsequently, all countries in the world have begun to study. Chinese scholars in the mid-90s of last century began experiments and research in this area, then the state began to attach importance to investment and research. At present, the technology has been developed in our country more mature.

\footnotetext{
* Corresponding author
} 


\section{INVERSION PRINCIPLE OF GPS}

The total amount of delay in the zenith troposphere is calculated from the zenith and wet delays:

$$
\mathrm{ZTD}=\mathrm{ZHD}+\mathrm{ZWD}
$$

Zenith static delay can be calculated using the Saastamoinen model:

$$
\begin{gathered}
\mathrm{ZHD}=(2.2768 \pm 0.0024) \frac{\mathrm{p}_{\mathrm{s}}}{\mathrm{f}(\varphi, \mathrm{H})} \\
\mathrm{f}(\varphi, \mathrm{H})=1-0.0266 \cos 2 \varphi-0.00028 \mathrm{H}
\end{gathered}
$$

In the formula, Ps is the pressure of station(hpa); $\mathrm{H}$ is the height of the earth station; $\varphi$ is the latitude of the station.

The delay of the wet delay in zenith direction can be expressed as:

$$
\mathrm{ZWD}=10\left[\mathrm{k}_{2} \int \frac{\mathrm{p}_{\mathrm{v}}}{\mathrm{T}} \mathrm{dz}+\mathrm{k}_{3} \int \frac{\mathrm{p}_{\mathrm{v}}}{\mathrm{T}^{2}} \mathrm{dz}\right]
$$

In the formula, $\mathrm{k}_{2}^{\prime}=\mathrm{k}_{2}-\mathrm{m} \times \mathbf{k}_{1} ;{ }_{\mathrm{m}=\frac{\mathrm{M}_{\mathrm{v}}}{\mathrm{M}_{\mathrm{d}}}}$, is water vapor and dry air The molar mass ratio.

The calculation formula of atmospheric precipitable water is:

$$
\mathrm{PWV}=\Pi \times \mathrm{ZWD}
$$

In the formula, $\Pi_{\text {is }}$ Water vapor conversion factor, It can be expressed as:

$$
\Pi=\frac{10^{-6}}{\rho_{w} R_{v}\left(k_{2}+k_{3} / T_{m}\right)}
$$

In the formula, $\rho_{w}$ is the density of liquid water is $1 \times 10-3 \mathrm{~kg} / \mathrm{m} 3 ; \quad \mathbf{R}_{\mathrm{v}}$ is a water vapor gas constant of $1 \times 103 \mathrm{~kg} / \mathrm{m} 3 ; \mathrm{K}_{2}=22.1 \mathrm{~K} / \mathrm{hpa}, \quad \mathrm{K}_{3}=3.739 \times 105 \mathrm{~K} 2 / \mathrm{hpa}$ is the atmospheric refraction constant; $\mathrm{Tm}$ is the atmospheric weighted average temperature.

\section{EXPREIMENT ANALYSIS}

\subsection{GAMIT solves the influence factor}

\subsubsection{Effect of initial coordinates}

The initial coordinate file has all the coordinates needed to be solved. The higher the accuracy of the initial coordinates, the higher the accuracy of solving the tropospheric delay. There are four ways to obtain the initial coordinates: $O$ file extraction, double difference positioning, single point positioning, ITRF framework extraction. In order to compare the accuracy of the four methods for the tropospheric delay, we selected the observation data of urum, lhaz and wuhn at the 152nd and 153rd days in 2013. The altitude of the satellite was set to $15^{\circ}$, and the VMF1 mapping function model was used. The ZTD of each station is calculated every two hours using the linear piecewise function method. Add data provided by CODE for comparative analysis. The result is as follows:

\begin{tabular}{|l|l|l|l|l|}
\hline $\begin{array}{l}\text { Origin of } \\
\text { the initial } \\
\text { coordinate }\end{array}$ & O file & $\begin{array}{l}\text { Single } \\
\text { point } \\
\text { positioning }\end{array}$ & $\begin{array}{l}\text { Double } \\
\text { difference } \\
\text { positioning }\end{array}$ & $\begin{array}{l}\text { ITRF } \\
\text { file }\end{array}$ \\
\hline $\mathrm{nrms}$ & 0.5254 & 0.20454 & 0.19254 & 0.18548 \\
\hline $\mathrm{X} / \mathrm{m}$ & \pm 0.0845 & \pm 0.0149 & \pm 0.0131 & \pm 0.0049 \\
\hline $\mathrm{Y} / \mathrm{m}$ & \pm 0.0762 & \pm 0.0142 & \pm 0.0120 & \pm 0.0075 \\
\hline $\mathrm{Z} / \mathrm{m}$ & \pm 0.185 & \pm 0.0198 & \pm 0.0185 & \pm 0.0059 \\
\hline
\end{tabular}

Table 1. Baseline solution results

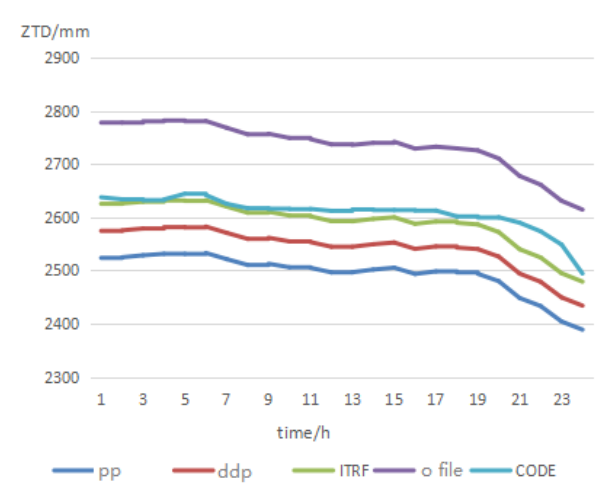

Figure 1. Comparison of different methods of obtaining coordinates (WHUN)

It can be seen from Table 1. and Figure 1. that the ZTD obtained by different methods of obtaining the initial coordinates has a great influence. The initial coordinate nrms obtained by the $\mathrm{O}$ file is 0.47 , far exceeding 0.25 , which is not reliable. The use of the other three methods to solve the nrms accuracy requirements, and little difference between each other, a great correlation. In comparison with CODE, it can also be seen that the use of ITRF to obtain the initial coordinates are the most similar. It is concluded that when the selected station is an IGS station, the initial coordinates are directly extracted from the ITRF framework and the estimated accuracy of the tropospheric delay is high. When the non-IGS site is selected, the double-difference positioning method can be used.

\subsubsection{Satellite ephemeris choice}

Included in satellite orbit satellite ephemeris, accurate orbit information is the basis for accurate positioning. The broadcast ephemeris updates every hour to meet real-time requirements, but the orbit accuracy is too low, so the tropospheric delay estimated using broadcast ephemeris can not reach the accuracy we need. Now, some organizations and departments each set up a ground tracking station, and the ephemeris calculated from the measured precision observation data is called a precise ephemeris. Although less than an hour after the broadcast ephemeris update time, but the orbit accuracy can reach centimeter level, the longer the lag the higher the general accuracy. The currently used ephemeris is the three ephemeris provided by IGS, an international GNSS service organization. They are IGS, IGR and IGU. Among them, after the precision precision ephemeris highest, but have to wait until 13 days -15 
days to obtain, and forecast precision ephemerides can be updated four times a day to meet the real-time requirements of the inversion of water vapor, but the orbit precision than ex post precise ephemeris, only Can reach the decimeter level.

In order to compare the differences between the posteriori precise ephemeris and the precise ephemeris forecast, we selected the observed data of 161st-161st days of 2013 from IGS stations bjfs, urum, shao, kunm and lhaz, The altitude of the satellite is $15^{\circ}$ at the elevation angle, and the initial coordinate constraint is set to $0.05 \mathrm{~m}$ using the VMF1 function model. The Saastamoinen model is used to calculate every $1 \mathrm{~h}$ with the piecewise linear function. Other parameters default to. The ephemerides of IGS and IGU are respectively used to calculate the ZTD of wuhn station, and CODE data is added for comparison. The results shown in Fig 2.:

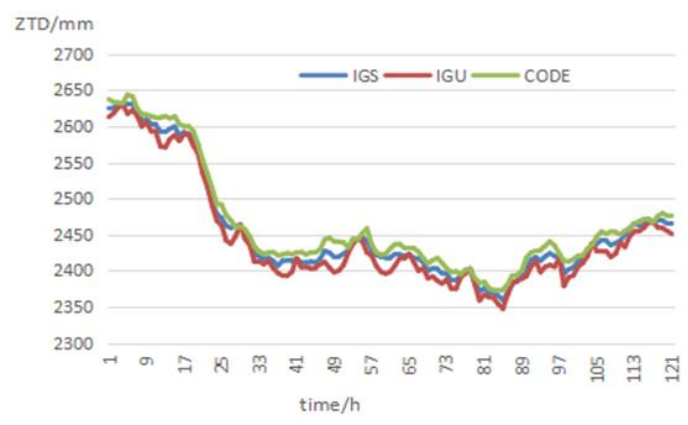

Figure 2. ZTD alignment diagram

It can be seen from Fig 2. that the results provided by CODE at ZhanDu Station, Precise Ephemeris and Precise Ephemeris derived from ZTD and IGS analysis center are consistent with the trend of change and overall characteristics, and have good coincidence degree. This shows that the accuracy of the ZTD using the predicted precision ephemeris and the COT provided by the IGS analysis center using the precision ephemeris estimated ZTD are similar.

\subsubsection{Solve the choice of observations}

In the process of retrieving atmospheric water vapor, joint long baselines are often required for joint solution, with baselines reaching tens of kilometers in length and even some with baselines exceeding $500 \mathrm{~km}$. In this large-scale observational network, the double-difference method is not sufficient to eliminate the ionospheric delay, so we need to choose the best observation to solve for. The commonly used observations are shown in Table 2. The experimental data were selected from the observation data of the 161st days of six domestic IGS stations wuhn, lhaz, urum, shao, bjfs and chan, and the other parameters are the same as the previous section. The following four observations were chosen to solve the problem respectively. The results are shown in Table 3. and Figure 3..

\begin{tabular}{|l|l|}
\hline Observations & $\mid$ \\
\hline LC_HELP & $\begin{array}{l}\text { Dual frequency eliminates } \\
\text { ionospheric effects } \\
\text { LC Solution Based on } \\
\text { Codes to Solve Wide } \\
\text { Ambiguity } \\
\text { Solve ambiguitees using L1 } \\
\text { and L2 observatic } \\
\text { Solve ambiguities using } \\
\text { only L1 observations }\end{array}$ \\
\hline
\end{tabular}

Table 2. Selection of observations

\begin{tabular}{|c|c|c|c|c|}
\hline $\begin{array}{c}\text { Observat } \\
\text { ions }\end{array}$ & $\begin{array}{c}\text { LC_H } \\
\text { ELP }\end{array}$ & $\begin{array}{c}\text { LC_AUT } \\
\text { CLN }\end{array}$ & $\begin{array}{c}\text { LIL2_INDE } \\
\text { PEND }\end{array}$ & $\begin{array}{c}\text { L1_ON } \\
\text { LY }\end{array}$ \\
\hline Nrms & $\begin{array}{c}0.2116 \\
8\end{array}$ & 0.21168 & 0.54996 & 0.4460 \\
X/m & \pm 0.018 & \pm 0.0198 & \pm 0.0111 & \pm 0.012 \\
& 7 & & & 3 \\
$\mathrm{Y} / \mathrm{m}$ & \pm 0.022 & \pm 0.0234 & \pm 0.0118 & \pm 0.013 \\
& 1 & & & 1 \\
$\mathrm{Z} / \mathrm{m}$ & \pm 0.033 & \pm 0.0345 & \pm 0.0210 & \pm 0.023 \\
& 3 & & & 1 \\
\hline
\end{tabular}

Table 3. Observations on the accuracy of the baseline vector (wuhn-urum)

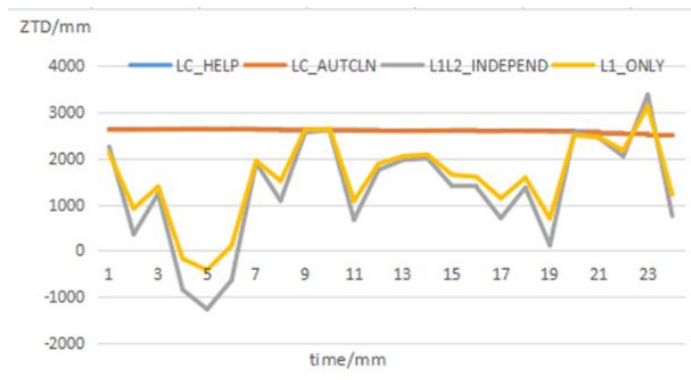

Figure 3. ZTD comparative analysis

This section selects the baseline from Wuhan to Urumqi these two stations as an example, Wuhan to Urumqi, the baseline for the $\mathrm{X}=-2460780.0744, \mathrm{Y}=402302.9209, \mathrm{Z}=-1172020.89$ can be seen from Table 4.3, although the choice of L1, L2_INDEPEND And L1_ONLY, the X, Y and Z resolutions of the baseline are slightly higher, but the root mean square residuals nrms are 0.54996 and 0.44608 , respectively. Generally, when nrms exceeds 0.3, this solution is problematic. The choice of LC_HELP and LC_AUTCLN two kinds of observations to calculate the nrms only 0.21168 , baseline solution to the $\mathrm{X}, \mathrm{Y}, \mathrm{Z}$ deviation is only less than $0.02 \mathrm{~m}$. Again, as can be clearly seen in Figure 3., the zenith tropospheric delay computed using the two observations L1, L2_INDEPEND and L1_ONLY is completely unreliable. However, the ZTD calculated by LC_HELP and LC_AUTCLN are nearly coincident, and the data of ZTD and CODE solved by LC_AUTCLN have been compared with each other. Therefore, the accuracy is reliable. 


\subsection{Ground - based GPS inversion of precipitable water} reflect climate change

\subsubsection{Water vapor inversion program}

As China is large in area and latitude and longitude are also relatively large, changes in water vapor in different cities are also greater in different regions. In order to analyze the distribution of water vapor in different regions of China, eight IGS sites (BJFS, CHAN, GUAO, TWTF, Urumqi, LHAZ Tibet Lhasa), SHAO (Shanghai Sheshan), WUHN (Hubei Wuhan)) in June 2013. Due to the large number of stations, this article takes Wuhan station as an example and analyzes the data. The coordinate data of each site is shown in Table 4.. Since most of the stations' baselines exceed $500 \mathrm{~km}$, the observer chooses LC_AUTCLN, the elevation angle of the satellite is $15^{\circ}$, the zenith tropospheric correction model and the static delay model are GAMIT's default Saastamoinen model, and the mapping function model uses VMF1, ephemeris After selecting the precise ephemeris, the initial coordinates of the station are extracted directly from the ITRF08 framework. Use the piecewise linear method to estimate the zenith troposphere delay every hour, and to process the pattern RELAX.

\begin{tabular}{|c|c|c|}
\hline Station name & Latitude/degree & Latitude/degree \\
\hline BJFS & 39.61 & 115.89 \\
\hline CHAN & 43.78 & 125.43 \\
\hline GUAO & 43.47 & 87.18 \\
\hline LHAZ & 29.66 & 91.11 \\
\hline SHAO & 31.92 & 121.2 \\
\hline TWTF & 24.95 & 121.16 \\
\hline URUM & 43.81 & 87.6 \\
\hline WUHN & 30.49 & 114.48 \\
\hline
\end{tabular}

Table 4. Station Coordinate Information

\subsubsection{Water vapor inversion accuracy verification}

Sounding station as the most reliable sounding means the current accuracy, often using this method to verify the accuracy of GPS inversion techniques. This article from the United States Wyoming University website to download the South Lake, Wuhan sounding station data. Because the sounding station launches the data of the sounding balloon at 0 o'clock and 12:00 o'clock every day, the water vapor data of the two time points retrieved at 0 o'clock and 12 o'clock are compared below to analyze the accuracy and reliability .

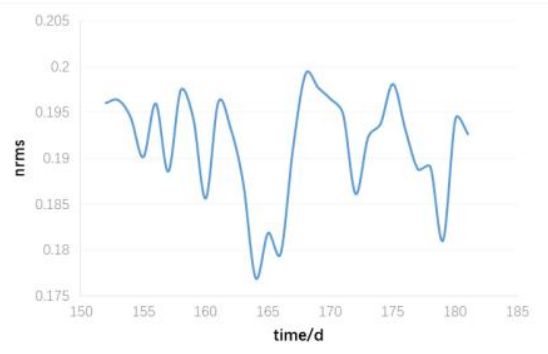

Figure 4. nrms
Nrms is used as an indicator to verify the baseline solution, obtained in the $\mathrm{O}$ file. In general, nrms less than 0.25 consider accuracy to be reliable. It can be seen from Figure 4 . that the root mean square residuals of this solution basically all fluctuate within the range of $0.175-0.2$, so it is determined that the solution accuracy is reliable.

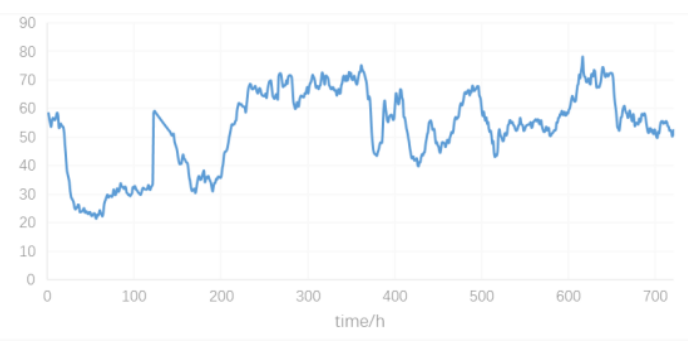

Figure 5. WUHN Station PWV

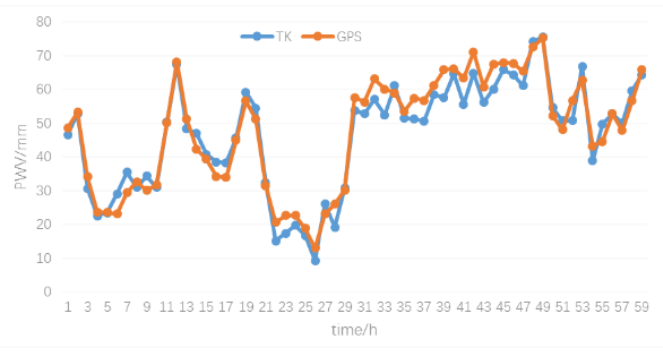

Figure 6. Wuhan sounding station and GPS inversion data comparison

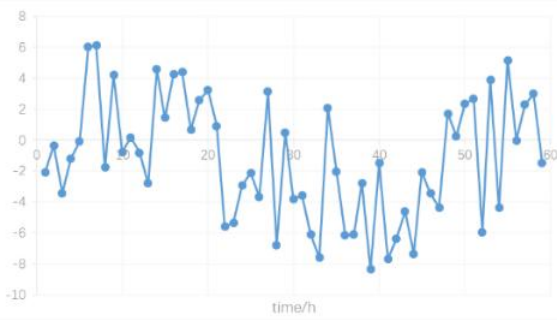

Figure 7. Wuhan sounding station and GPS inversion data difference

It can be seen from Figure 7. that the difference is basically between $-6 \mathrm{~mm}$ and $6 \mathrm{~mm}$, and the few points are smaller than $-6 \mathrm{~mm}$ with a certain error. It can be seen from Figure 6. that the trend of PWV measured by the two methods is almost the same, which proves that the inversion accuracy is reliable. As can be seen from Figure 6., from June 1, PWV decreased rapidly from $58 \mathrm{~mm}$ to $23 \mathrm{~mm}$ at 16 o'clock on June 3 , and then from January 6 to January 8, there was a clear Sudden surge process. PWV started to grow up to $70 \mathrm{~mm}$ at 10 o'clock 10 after the minimum of 0 at 9 o'clock on the 9 th. In the following days, the atmospheric water vapor content fluctuated between $60 \mathrm{~mm}-75 \mathrm{~mm}$. At $6: 00$ on the 16 th to $0: 00$ on the 17 th for the water vapor content of the process of decline. Subsequent period of time, the water vapor is also relatively wide range of changes, and water vapor content has also been in a relatively high state, are basically greater than $50 \mathrm{~mm}$, the highest reached $78 \mathrm{~mm}$, far exceeding the average water vapor content in 
Wuhan, indicating that during this time Wuhan, there will be heavy rain.

Based on the analysis of the water vapor in June 2013 in the above 8 stations, we know that the trend of water vapor is closely related to rainfall. When the sudden increase of PWV sharply declines, it indicates that heavy rain will occur. If the atmosphere's high water vapor content far exceeds the average water vapor in the area, it also indicates that this short period of time will be a rainy day.

\section{CONLUSION}

The three parts (initial coordinates, satellite ephemeris, observation value) that have a great influence on the delay of the troposphere are introduced. The related experiment is solved by GAMIT software. The experimental results show that when the station is an IGS station, the ITRF framework is used to directly extract the coordinate to calculate the best accuracy. When the station is an ordinary station, the coordinates can be obtained by double difference positioning to obtain the best solution accuracy. By using IGS and IGU The comparison between ephemeris and CODE data shows that the use of IGS ephemeris and IGU ephemeris and CODE data trends the same, and the difference is small, you can use the forecast precision ephemeris to forecast the weather effect; the solution observed values using LC_AUTCLN and LC_HELP accuracy is the best, should not be used L1, L2_INDEPEND and LC_ONLY.

Based on the ground-based GPS observations of the observation network consisting of 8 IGS stations in China in June 2013 and the ground meteorological data, the atmospheric water vapor values in this period of time in China were retrieved. Taking Wuhan Station as an example, the reliability of the system is verified by comparing with the water vapor data of the sounding station on the ground.

\section{REFERENCES}

Braun John, Joseph. Remote Sensing of Atmospheric Wate Vapor with theGlobal Positioning System[D]. Faculty of the Graduate Sehool of the University of Colorado, 2004

Businger S, Chiswel S, Bevis M, et al. The promise of GPS in atmospheric monitoring. Amer-Meteor-Soc, 1996, 17 (1): 5-18

Chuang Wang, Research and Application of Ground Based GPS Technique to Retrieve Atmospheric Water Vapor[M], Changsha University of Science and Technology,2011

EMARDSON T R, JOHANSSON J, ELGERED G.The systematic behavior of water vapor estimates $\mathrm{u}$-sing four years of GPS observations [J] .IEEE Transac -tions on Geoscience and Remote Sensing , 2000 , 38 ( 1 ):324 - 329

Gradinarsky ,Bouma H R ,Scherneck ,et al.Climate monitoring using GPS.Phys.Chem.Earth,2002,27:335-340

Mazany R A, Businger S, Gutman A I, et al. A Lighting Prediction Index that Utilizes GPS Integrated Precipitable Water Vapor. Weather and Forecasting, 2002, 17: 1034-1047

Yan Han, Ground - based GPS water vapor detection and its application,Chengdu University of Technology,2012
Yuan,Anthes R A,Ware R H,et al.Sensing climate change using the Global Positioning System.Geophys Res,2000,98:14925-14937. 
The International Archives of the Photogrammetry, Remote Sensing and Spatial Information Sciences, Volume XLII-3, 2018 ISPRS TC III Mid-term Symposium "Developments, Technologies and Applications in Remote Sensing”, 7-10 May, Beijing, China 